\title{
Bone Marrow Cells in X-linked Agammaglobulinemia Express Pre-B-specific Genes ( $\lambda$-like and V Pre-B) and Present Immunoglobulin V-D-J Gene Usage Strongly Biased to a Fetal-like Repertoire
}

\author{
Michèle Milili, ${ }^{*}$ Françoise Le Deist, ${ }^{*}$ Geneviève de Saint-Basile, ${ }^{*}$ Alain Fischer, ${ }^{*}$ Michel Fougereau, ${ }^{*}$ and Claudine Schiff * \\ *Centre d'Immunologie Institut National de la Santé et de la Recherche Médicale (INSERM) Centre National de la Recherche \\ Scientifique (CNRS) de Marseille-Luminy, 13288 Marseille Cedex 9, France; and ${ }^{\ddagger}$ Unité INSERM U132, Hôpital des Enfants Malades, \\ 75743 Paris Cedex 15, France
}

\begin{abstract}
Expression of Ig and Ig-related genes has been studied in bone marrow cells from two patients with severe form of $\mathrm{X}$-linked agammaglobulinemia (XLA). Phenotypic analysis revealed the presence of pre-B cells, in the absence of mature $B$ cell markers. The pre-B-specific genes, $\lambda$-like and $V$ pre-B, were normally transcribed. Sequence analysis of 48 distinct $V-D-J$ cDNA clones directly derived from XLA bone marrow cells indicated that they had characteristics of an early fetal pre-B repertoire. All VH families were identified, with a strong bias in the gene usage: a few VH genes were largely overexpressed, either germline or slightly mutated; most genes had been located $3^{\prime}$ of the VH locus and were also used in fetal liver (8-13 wk of gestation). Short $D$ regions, (resulting from D-D fusion, making usage of all $\mathrm{D}$ genes in both orientations with utilization of the three reading frames), restricted $\mathrm{N}$ diversity, and a fetal JH usage pattern were also observed. Taken together, our data suggest that the XLA defect does not alter V-D-J rearrangements nor the expression of $\mu, \lambda$-like, and $V$ pre-B transcripts and most likely results in a poor efficiency of some critical steps of the B cell maturation. (J. Clin. Invest. 1993.91:1616-1629.) Key words: immunoglobulin • immunoglobulin-related gene expression • primary immune deficiency
\end{abstract}

\section{Introduction}

X-linked agammaglobulinemia (XLA) ${ }^{1}$ is a primary immune deficiency characterized by a severe impairment of immunoglobulin synthesis correlated with a low number of mIgM-positive B lymphocytes and by the lack of plasma cells ( reviewed in references 1 and 2 ). Analysis of the $X$ chromosome inactivation in XLA carrier women has shown that the defect was specific to the B cell lineage (3-7). The exact nature of the defect is, however, not known. B precursors characterized by early markers such as TdT, CD10, and CD19(8) are present in

Address reprint requests to $\mathrm{Dr}$. Claudine Schiff, Centre d'Immunologie INSERM CNRS de Marseille-Luminy, Case 906, 13288 Marseille Cedex 9, France.

Received for publication July 8, 1992 and in revised form 29 October 1992.

1. Abbreviation used in this paper: XLA, X-linked agamma-globulinemia.

J. Clin. Invest.

(C) The American Society for Clinical Investigation, Inc.

$0021-9738 / 93 / 04 / 1616 / 14 \$ 2.00$

Volume 91, April 1993, 1616-1629 the bone marrow. Although truncated heavy chains have been identified earlier (9), the recombinases that direct Ig and T cell receptor (TCR) gene rearrangement do not seem to be affected by the XLA gene since the T cell compartment appears to be normal (8). More recent reports have shown that the IGH locus could recombine, and that some Epstein-Barr virus (EBV)-transformed cell lines could be derived from XLA patients, suggesting that block of the B cell maturation was leaky $(3,10-13)$.

Ig gene expression necessitates rearrangements that occur according to an apparently strict ordered program $\mathrm{H} \rightarrow \kappa \rightarrow \lambda$ (14). Studies using transgenic mice (15) and gene targeting (16) have clearly shown that each step is controlled by the successive Ig gene products in their membrane form. Expression of the $\mu$ chain at the surface of pre-B cells has been shown to take place through the so-called $\mu-\psi \mathrm{L}$ complex in which the regular L chain is replaced by the product of two genes, specifically expressed in pre-B cells, termed $V$ pre-B and $\lambda$-like (1722 ). Because the XLA defect seems largely characterized by an impairment of the early steps of B cell differentiation, we have studied the expression of Ig and Ig-related genes in non transformed bone marrow cells isolated from XLA patients. Our results indicate that there is no major impairment at the pre-B stage. The $\lambda$-like and $V$ pre-B genes are expressed, and the $H$ chain repertoire makes use of all $\mathrm{VH}$ families, with a pattern of expression that resembles that of the fetal tissues. This observation, taken together with the fact that some level of light chain rearrangement takes place, suggests that the XLA defect most likely resides in a poor efficiency of a critical step of the B cell maturation, independent of the Ig gene recombination machinery.

\section{Methods}

Cases report. Bone marrow from two XLA patients was used in this study. Patient L.E. was a 3-yr-old boy with recurrent otitis and gastroenteritis from the age of 3 mo. Blood cell counts showed neutropenia and normal amount of lymphocytes. Serum immunoglobulin levels were below detection threshold $(0.07 \mathrm{mg} / \mathrm{ml}$ for IgG, IgM, and IgA ). No B cell, as appreciated from the lack of mIgM positive cells, was found. Diagnosis of XLA was confirmed by the X inactivation pattern analysis of the mother cells using methylation sensitive enzyme and restriction fragment length polymorphism (RFLP) study (5). A skewed pattern of $X$ inactivation was observed in the mother EBV-derived $B$ cell lines while $T$ lymphocytes and polymorphonuclear cells displayed the expected random pattern. Patient R.S. was a 20-yr-old man with recurrent upper and lower respiratory tract infection. Serum immunoglobulin levels were below detection threshold and no mIgMpositive cells were detected in blood samples.

Surface marker analysis. Cells were isolated from freshly drawn heparinized bone marrow by means of Ficoll-Hypaque (Pharmacia Fine Chemicals, Uppsala, Sweden ) density gradient centrifugation. Flu- 
orescence staining was performed using the following antibodies: CD19 (IOB4, IgG1), CD21 (IOB1a, IgG1), CD22 (IOB22, IgG1), CD24 (IOB3, IgG1), CD34 (IOM34, IgG1), from Immunotech, Marseille, France and anti-mIgM (Caltag, San Francisco, CA). Direct fluorescence staining was performed using PE- or FITC-conjugated $\mathrm{mAb}$ (CD19, CD34). Indirect immunofluorescence staining (CD21, CD22, CD24) was performed using a FITC- or PE-conjugated goat antimouse Ig (Gamig, Nordic, Tilburg, The Netherlands). The analysis was performed using a FACSCAN (Becton, Dickinson \& Co., Mountain View, CA), on cells gated to exclude myeloid cells.

Preparation of cDNAs. Extraction of RNA from $2 \times 10^{6}$ bone marrow XLA or normal cells was performed by the guanidinium thiocyanate method followed by centrifugation in cesium chloride solution, according to Sambrooke et al. (23), as indicated in detail elsewhere (24). cDNA was prepared from $2 \mu \mathrm{g}$ of total RNA, using $0.8 \mu \mathrm{g}$ of oligo dT as primer and the reverse transcriptase of Bethesda Research Laboratories (Cergy-Pontoise, France) used according to the manufacturer's instructions.

PCR analysis. PCR was performed in a Perkin-Elmer Cetus (Norwalk, CT) apparatus, following the manufacturer's instructions, and using $500 \mathrm{ng}$ of cDNA with $50 \mathrm{pmol}$ of the appropriate oligonucleotides. Amplified products were run in agarose gel made $2 \%$ in $1 \times 0.089$ $M$ Tris, $0.089 \mathrm{M}$ Borate, and $2.5 \mathrm{mM}$ EDTA (TBE) and transferred on Hybond $\mathrm{N}$ membrane in $20 \times$ SSC and characterized upon hybridization with specific probes.

Experimental conditions used for the analysis of the pre-B-specific gene expression were previously described using non saturating substrate concentrations, i.e., between 100 and 500 ng of RNA (24) and led to the identification of specific fragments of 210 and $190 \mathrm{bp}$ for $\mathrm{V}$ Pre-B and $\lambda$-like amplification products, respectively. Normalization by reference to normal bone marrow cells was introduced using amplification of actin RNA. In addition, for each series of PCR, control samples of RNA from one positive cell ( Nalm-6, a pre-B cell line) and two negative cells ( 1SP3, an EBV-derived cell clone and Jurkat, a T-cell line) were run in parallel. A blank containing no input RNA was also included.

Analysis of the $\kappa$ transcripts was performed following the same conditions, using in separate experiments oligonucleotides corresponding to the four different family-specific $V_{\kappa}$ segments $(25)$ and to the $5^{\prime}$ terminal section of the $C_{\kappa}$ coding sequence (linker sequences are italicized):

\section{$\mathrm{V}_{\kappa} 1:\left(5^{\prime} A T C C G C G G A C A T C C A G A T G A C C C A G T C 3^{\prime}\right)$ \\ V $\kappa 2:$ (5'ATCCGCGGATATTGTGATGACTCAGTC3') \\ $\mathrm{V}_{\kappa} 3:\left(5^{\prime}\right.$ ATCCGCGGAAATTGTGTTGACGCAGTC3') \\ $\mathrm{V}_{\kappa} 4:$ ( 5'ATCCGCGGACATCGTGATGACCCAGTC3') \\ C $\kappa$ ( (5'ATGCGGCCGCGGGAAGATGAAGACAGATG3')}

The amplified products were checked with a $\mathrm{J}_{K}$ probe. A blank containing no input RNA was also included.

Construction of cDNA libraries and identification of the cDNA clones. VH transcripts from patient R.S. were cloned after anchored PCR. cDNA between 0.5 and $2 \mathrm{~kb}$ were purified by electrophoresis on $0.8 \%$ low melting point agarose in $1 \times \mathrm{TBE}$ and oligo dG tailing was performed as described by Loh et al. (26) with TdT (Bethesda Research Laboratories) for $20 \mathrm{~min}$ at $37^{\circ} \mathrm{C}$. Amplification was performed with 2.5 units of Taq polymerase (PROMEGA) in $100 \mu$ l of the standard buffer and 50 pmol of each oligomer (linkers are italicized):

linker-oligo dC:

\section{( 5'ATGCATGCCGCGGCCGCCCCCCCCCCCCC3')}

$\mathrm{C} \mu$ linker:

\section{( 5'ATCCGCGGCCGCGGAATTCTCACAGGAGACGA3')}

for 30 cycles in a Perkin Elmer Cetus apparatus with the following program: first cycle $94^{\circ} \mathrm{C}, 3 \mathrm{~min} ; 50^{\circ} \mathrm{C}, 4 \mathrm{~min} ; 72^{\circ} \mathrm{C}, 2 \mathrm{~min} ; 10$ cycles $94^{\circ} \mathrm{C}, 1.5 \mathrm{~min} ; 50^{\circ} \mathrm{C}, 4 \mathrm{~min} ; 72^{\circ} \mathrm{C}, 2 \mathrm{~min} ; 19$ cycles $94^{\circ} \mathrm{C}, 1.5 \mathrm{~min}$; $55^{\circ} \mathrm{C}, 4 \mathrm{~min} ; 72^{\circ} \mathrm{C}, 2 \mathrm{~min}$ except for the last cycle for which the final extension at $72^{\circ} \mathrm{C}$ proceeded for $10 \mathrm{~min}$. The amplified material was separated on $1 \%$ low melting point agarose gel and the fraction contained within the $0.3-$ and $0.6-\mathrm{kb}$ range was isolated. One-tenth of this material was amplified with the same primers for 40 cycles at $58^{\circ} \mathrm{C}$. Amplified products were precipitated and the resulting DNA was digested with NotI, ligated in NotI-treated and dephosphorylated bluescript vector (Stratagene, Inc., La Jolla, CA). Transformation was performed in JM 101 by electroporation (27). Resulting colonies were screened with the $\mathrm{JH}$ probe.

VH transcripts from patient L.E. were cloned by PCR using, in separate experiments, oligonucleotides corresponding to the different family specific $\mathrm{VH}$ leader segments and to the 5 ' terminal section of the $\mathrm{C} \mu$ coding sequence (linkers are italicized):

VH1:

( 5'AAAGCGGCCGCATGGACTGGACCTGGAGGGTC3')

VH2/VH4:

( 5'ATCCGCGGCCGCATGAAACACCTGTGGTTCTT3')

VH3:

( 5'AAAGCGGCCGCATGGAGTTTGGGCTGAGCTGG3')

VH5:

( 5'AAAGCGGCCGCATGGGGTCAACCGCCATCCTC3')

VH6:

( 5'AAAGCGGCCGCATGTCTGTCTCCTTCCTCATC3')

$\mathrm{C} \mu$ :

( 5'ATCCGCGGCCGCGGAATTCTCACAGGAGACGA3').

for 30 cycles in a Perkin-Elmer Cetus apparatus with the following programme: first cycle: $94^{\circ} \mathrm{C}, 3 \mathrm{~min} ; 60^{\circ}, 3 \mathrm{~min} ; 72^{\circ}, 3 \mathrm{~min} ; 29$ cycles: $94^{\circ}, 1.5 \mathrm{~min} ; 60^{\circ}, 3 \mathrm{~min} ; 72^{\circ}, 3 \mathrm{~min}$ except for the last cycle for which the final extension at $72^{\circ} \mathrm{C}$ proceeded for $10 \mathrm{~min}$. The amplified material was separated on $1 \%$ low melting point agarose gel and the fraction at $0.45 \mathrm{~kb}$ was isolated. One-tenth of this material was amplified with the same primers for 30 cycles at $60^{\circ} \mathrm{C}$. Amplified products were digested with NotI, and cloned as above. Resulting colonies were screened with the VH-specific probes.

DNA sequencing. DNA sequencing was performed by the dideoxy chain termination protocol (28) using ${ }^{35} \mathrm{SdATP}$ and a DNA sequencing system-T7 DNA polymerase (Amersham International, Amersham, $\mathrm{UK}$ ). Inserts were sequenced using $\mathrm{T} 3$ and $\mathrm{T} 7$ oligonucleotides.

DNA probes. IgC $\lambda$ is a genomic $0.7-\mathrm{kb}$ EcoRI-HindIII fragment containing the $C \lambda 3$ gene (29) obtained from Dr. M.-P. Lefranc (Montpellier II University, Montpellier, France) and was used to identify the cross-reactive $\lambda$-like gene product. $\mathrm{V}$ pre- $\mathrm{B}$ is an amplified product from amino acid residues $50-120$ of the coding region (22). $\mathrm{JH}(0.5 \mathrm{~kb}$ SacI) (30) and $J_{K}$ ( $2 \mathrm{~kb}$ Sstl ) (31) genomic probes were gifts from Dr. P. Leder (Harvard Medical School, Boston, MA). VH1 (0.3 kb PstIEcoRI from pVE3-D10) and VH2 (1.2 kb EcoRI-EcoRV from pVCE1) genomic probes were obtained from Dr. T. Honjo, Faculty of Medicine, Kyoto, Japan (32). VH3 (0.32 kb EcoRI-HaeIII from $\gamma$ F9 cDNA (33), VH4 (0.33 kb PstI from 1-911), VH5 (0.38 kb HincIIPstI from 5-1R1), and VH6 (0.3 kb EcoRI-StuI from 6-1R1) genomic probes were given by Drs. J. Berman and F. Alt, Howard Hughes Medical Institute, Boston, MA (34).

\section{Results}

Phenotypic characterization of bone marrow XLA cells. FACS analysis of bone marrow cells from one patient (L.E.) is given 

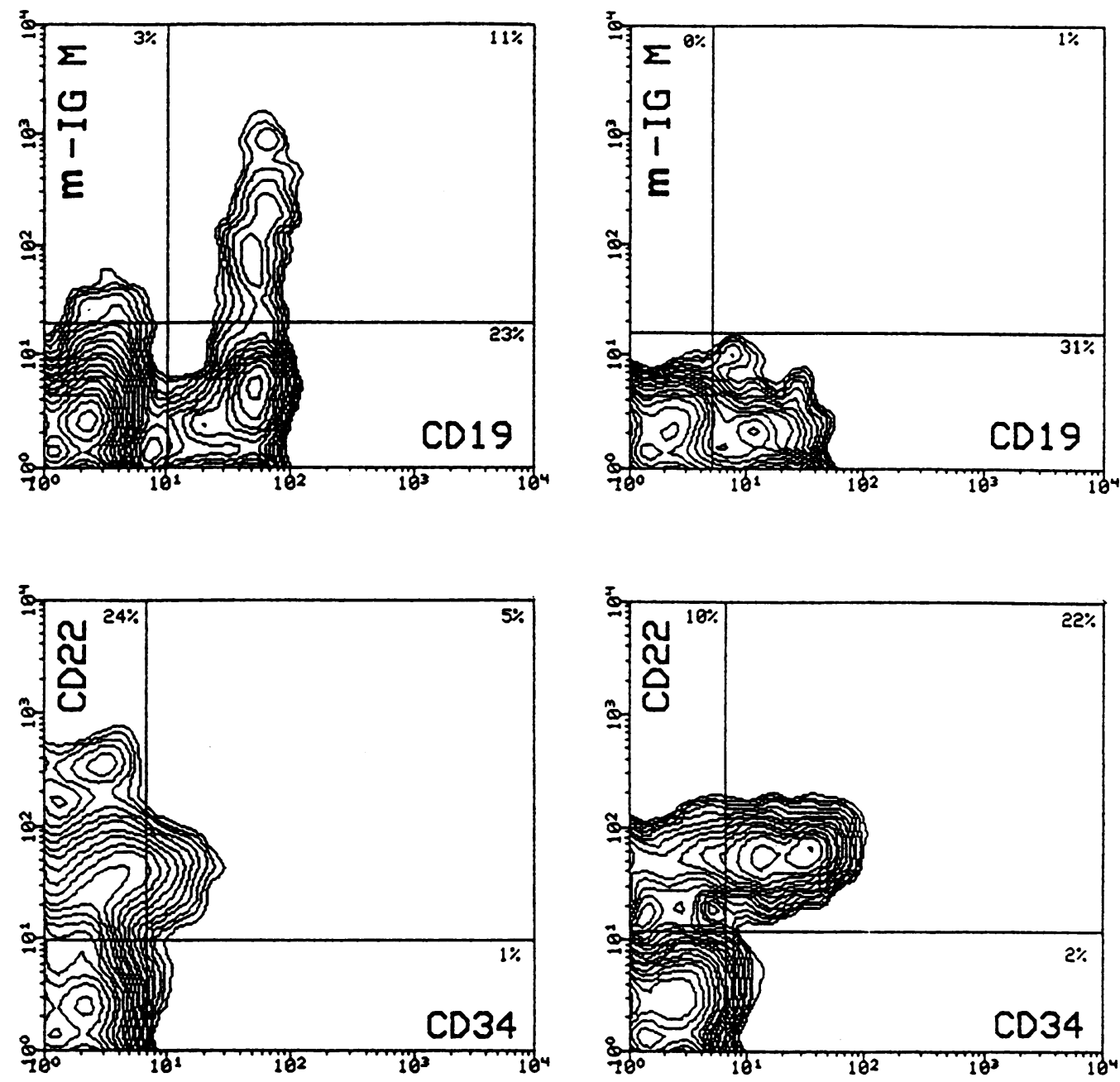

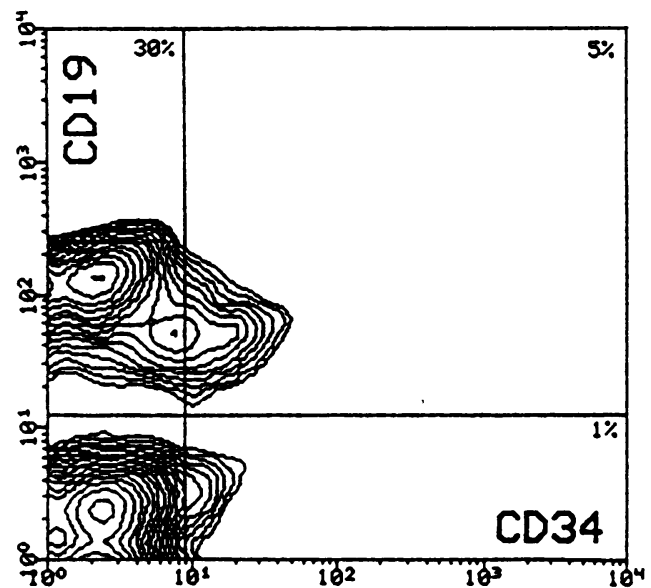

a Normal

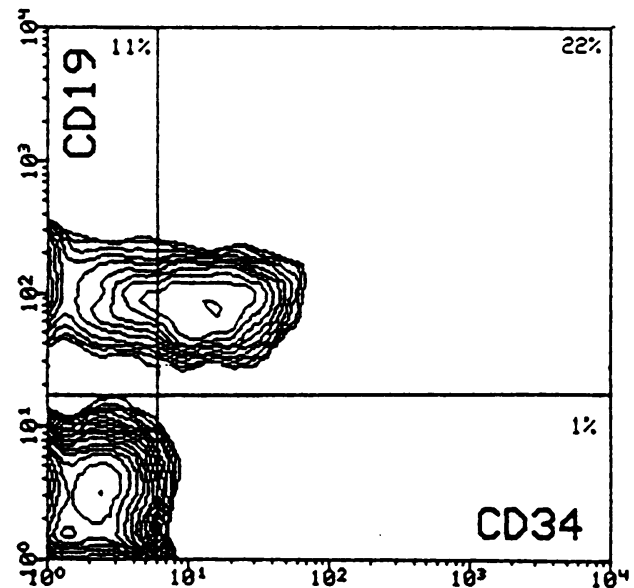

b XLA
Figure 1. FACS analysis of $(a)$ normal and $(b)$ XLA bone marrow cells. CD19, CD34, mIgM were identified respectively with $\mathrm{PE}$-conjugated IOB4, FITC-conjugated IOM34, and anti-IgM by direct immunofluorescence. CD22 was tested with IOB22 by indirect immunofluorescence using a FITCconjugated GAMIG. Fluorescence intensity was expressed on a log scale. Analysis was performed on cell gate to exclude myeloid cells. in Fig. 1. No mIgM was detected, whereas $\sim 33 \%$ of the cells was found positive for CD19 and/or CD22. From these, $66 \%$ were found double-positive with respect to the CD34 marker, as opposed to $14 \%$ in normal bone marrow cells. By contrast all
XLA cells were negative for CD2 1 and CD24 (33\% and 37\% in the controls, respectively, data not shown ). In addition, immunofluorescence revealed some cells with intracytoplasmic $\mu$ chains ( $9 / 500$ mononuclear cells) whereas no intracytoplas- 
mic light chain $(\kappa+\lambda)$ was detected. Cells from patient R.S. were checked only for mIgM, and were all found negative.

Expression of the $\lambda$-like and $V$ pre- $B$ genes. To normalize the amount of RNA used for $\lambda$-like and $V$ pre-B amplification from both XLA and normal bone marrow cells, we first performed a PCR analysis using serial dilutions of RNA and actinspecific oligonucleotides (data not shown). Ranges covering $500-100 \mathrm{ng}$ from both RNAs were then amplified with $\lambda$-like or $\mathrm{V}$ pre-B specific oligonucleotides. In Fig. $2 a$ is reported the $\lambda$-like PCR pattern obtained for 500,400 , and $300 \mathrm{ng}$ of both cDNAs. Specific bands were identified at $190 \mathrm{bp}$ with the same decrease in intensity for the two samples. No signal was recovered at lower concentrations, as already reported (24). V pre-B and $\lambda$-like PCR patterns obtained with $500 \mathrm{ng}$ of normal and XLA bone marrow cells are given in Fig. $2 b$. The 210-bp (VpreB) and 190-bp ( $\lambda$-like) specific bands have similar intensities, whichever their origin. Similar results were obtained for the two XLA patients clearly suggesting that the two pre-B specific genes were normally expressed on a quantitative basis in XLA patients.

Analysis of the V-D-J repertoire in XLA bone marrow cells. RNA from Ficoll purified bone marrow cells from patient R.S. was amplified by anchored PCR using a $5^{\prime} \mathrm{C} \mu$-specific oligonucleotide, yielding nine different sequences, of which six were of the V-D-J type with variable VH lengths, one was of the D-J$\mathrm{C} \mu$ form (RS 54), and two (RS 39 and RS 51) for which presence of $\mathrm{VH}$ residues could not be determined due to the limited size of the transcripts (Table I). In order to select for complete transcripts, RNA from patient L.E. was amplified using $5^{\prime} \mathrm{C} \mu$ and each of the leader VH-specific oligonucleotides. 143 clones were sequenced, from which 39 different V-D-J sequences were identified and are listed according to the $\mathrm{VH}$ family grouping in Table I. Most sequences were obtained several times from different clones (between two and nine), with identical results. The complete sequences have been deposited at the EMBL data bank (accession nos. X65883-X65920).

It can be observed that all $\mathrm{VH}$ families are used except VH2, which was earlier shown to be poorly expressed in the normal Ig repertoire (38). Within each family, all transcripts were assigned to one of the known germline genes, taken from
EMBL data bank or from recently published data (36) as indicated in Table I. The number of nucleotide substitutions necessary to derive the cDNA sequences from the known germline genes is also indicated. In most cases, fewer than 10 mutations, that occurred randomly all along the VH segment, were suffcient to derive most expressed sequences from the germline genes. $40 \%$ of the transcripts had two mutations or fewer, including six sequences that were completely germline. Alternatively, minor nucleotide substitutions may be due to allelic polymorphism as illustrated by comparison with the data of Shin et al. (35). On the basis so defined, gene usage within each family clearly appears restricted. For instance, in the VH1 family, six different germline genes accounted for the 13 reported sequences, of which gene 1-3b (35) was encountered six times. Four genes were used in a total of $11 \mathrm{VH} 4$ sequences, V 79 being present seven times (37).

Sequences encompassing the CDR3 regions are presented in Fig. 3 according to the JH usage. Assignment of D segments was defined using homology with direct and reverse $D(40-42)$ and DIR (DH gene containing irregular spacer signals [43]) germline sequences on the basis of a minimal length of six identical nucleotides or seven nucleotides with no more than one mismatch. It can be seen on Fig. 4 that the expressed D segments could be derived from one single germline gene $(47 \%$ of the sequences) to up to four $D$ genes resulting from multiple fusions. Both direct and reverse sequences were identified, with occasional usage of DIR genes. Three sequences did not match any of the known D genes. Most D genes were expressed ( Table II), of which $27 \%$ in the reverse orientation. The DXP family accounted for $38 \%$ of the total. The three reading frames were used, although reading frame 2 was used more frequently.

Detailed organization of the CDR3 regions is given in Fig. 3 . $N$ sequences were introduced whenever no nucleotide counterpart could be identified on either of the $\mathrm{V}, \mathrm{D}$, or $\mathrm{JH}$ germline segments. Finally, whenever nucleotides could undifferently fit with $3^{\prime} \mathrm{V}$ or $5^{\prime} \mathrm{D}$ and/or with $3^{\prime} \mathrm{D}$ or $5^{\prime} \mathrm{J}$, they were arbitrarily assigned to $\mathrm{V}$ or to $\mathrm{J}$, respectively. On these grounds, $\mathrm{N}$ diversity, with possible $P$ diversity (39), appeared very limited, since it was absent in over $40 \%$ of either the V-D and the D-J junctions. When present, the $\mathrm{N}$ diversity segment averaged four a

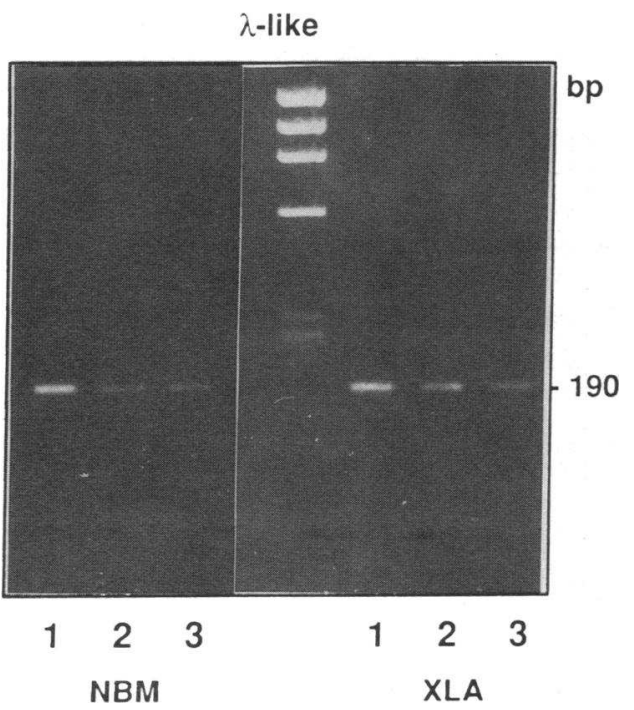

b

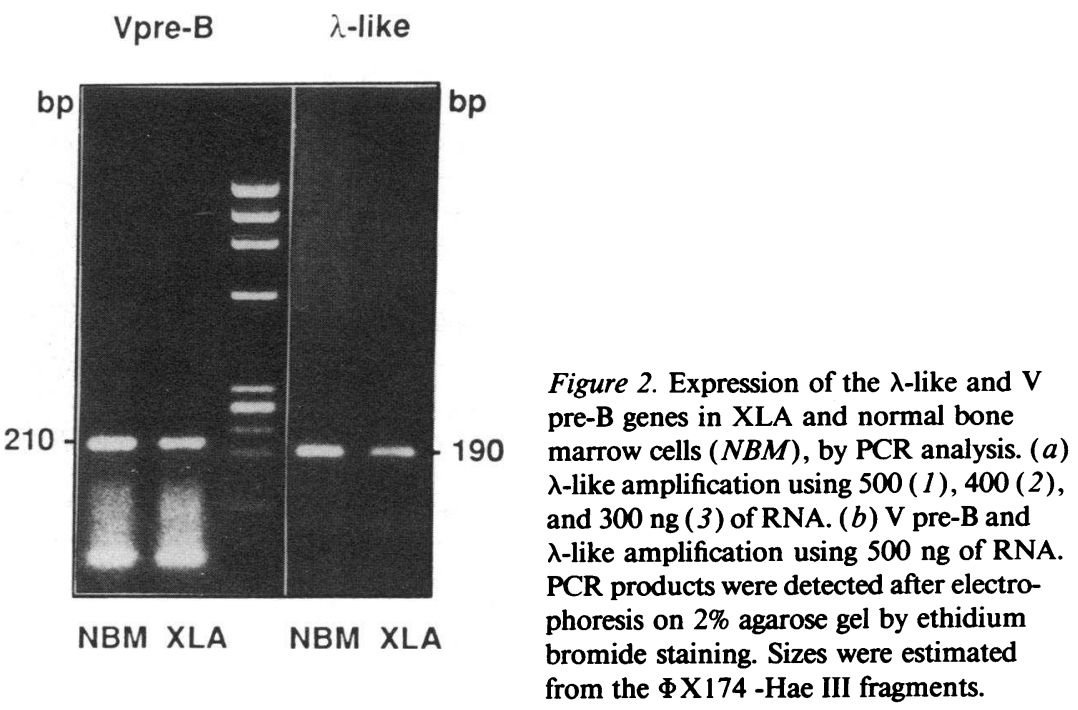




\begin{tabular}{|c|c|c|c|c|c|c|c|c|c|c|}
\hline & \multicolumn{3}{|c|}{ VH } & $\mathbf{N}$ & DH & $\mathbf{N}$ & JH & $\begin{array}{l}\text { Length } \\
\text { N-D-N }\end{array}$ & $\begin{array}{l}\text { Length } \\
\text { CDR3 }\end{array}$ & I/O \\
\hline LE 1-6 & $1^{*}$ & $1-4 b^{\ddagger}$ & $(3)^{8}$ & & & & 6 & 0 & $30^{\prime}$ & $\mathrm{in}^{* *}$ \\
\hline RS $1-103$ & 1 & $1-8$ & (1) & & $\mathrm{D} 23 / 7$ & & 3 & 7 & 27 & out \\
\hline LE $1-17$ & 1 & $1-3 b$ & (1) & & $\mathrm{DIR}^{\ddagger}$ & & 3 & 8 & 30 & in \\
\hline LE $1-25$ & 1 & $1-46$ & (5) & & DHFL16 & 5 & 3 & 13 & 30 & in \\
\hline LE 1-54 & 1 & $1-46$ & (5) & & DHFL16 & 5 & 3 & 13 & 30 & in \\
\hline LE 1-10 & 1 & $1-3 b$ & (5) & & DHFL16 & 5 & 3 & 13 & 30 & in \\
\hline LE $1-100$ & 1 & $1-46$ & (6) & & DHFL16 & 5 & 4 & 13 & 30 & in \\
\hline LE 1-9 & 1 & $1-3 b$ & (0) & & DHFL16 & 6 & 4 & 14 & 27 & in \\
\hline RS $1-92$ & 1 & partia & & $8^{\prime \prime}$ & DHQ52 & 2 & 3 & 17 & 36 & in \\
\hline LE $1-82$ & 1 & $1-3 b$ & (2) & 2 & DK4 $4^{\ddagger \ddagger}-\mathrm{DM} 2^{\ddagger \ddagger}$ & & 6 & 18 & 42 & in \\
\hline LE $1-29$ & 1 & $1-2$ & (7) & 3 & DIR1-DLR4 ${ }^{\ddagger \ddagger}$ & & 4 & 20 & 33 & in \\
\hline LE $1-42$ & 1 & $1-3 b$ & $(0)$ & 6 & DK1 & & 6 & 20 & 51 & in \\
\hline LE $1-76$ & 1 & $1-3 b$ & (0) & & DIR1-D23/7-DK1-DXP'1 & & 4 & 31 & 51 & in \\
\hline LE $1-23$ & 1 & $1-3$ & (4) & & deleted & & deleted & & & \\
\hline LE 3-1 & 3 & $3-13$ & (4) & & unknown & & 6 & 4 & 21 & in \\
\hline LE 3-2 & 3 & $3-30$ & (2) & & unknown & & 6 & 4 & 21 & in \\
\hline LE 3-13 & 3 & $3-7$ & (3) & & DK1 & 1 & 6 & 8 & 33 & in \\
\hline RS 3-128 & 3 & partia & & 2 & DK4-D21/7 & & 4 & 19 & 39 & \\
\hline LE 3-21 & 3 & $3-30$ & $(2)$ & 2 & D21/7 $7^{\ddagger \pm}$ DHQ52 & 6 & 4 & 24 & 39 & out \\
\hline LE 3-12 & 3 & $3-23$ & (4) & & D21/7-DIR $1^{\ddagger}$ & & 4 & 25 & 42 & in \\
\hline LE 3-11 & 3 & partia & & 6 & DN1-D21/05 & 3 & 4 & 25 & 42 & \\
\hline LE 3-20 & 3 & $3-23$ & (7) & 6 & DN1-D21/05 & 3 & 4 & 25 & 42 & in \\
\hline LE 3-16 & 3 & $3-64$ & (9) & 4 & DXP4 & 1 & 4 & 26 & 42 & in \\
\hline LE 3-15 & 3 & $3-11$ & (9) & 11 & $\mathrm{D} 21 / 9$ & 5 & 3 & 35 & 54 & out \\
\hline LE 4-5 & 4 & V79 & (7) & 1 & DHFL16 & & 6 & 12 & 42 & in \\
\hline LE 4-30 & 4 & V79 & (2) & 3 & DHFL19 & & 5 & 12 & 36 & in \\
\hline LE 4-89 & 4 & $4-39$ & (8) & & unknown & & 3 & 20 & 42 & in \\
\hline LE 4-103 & 4 & V11 & (7) & 3 & $\mathrm{D} 21 / 9$ & & 3 & 21 & & \\
\hline LE 4-63 & 4 & V79 & (10) & 3 & DIR $1^{\ddagger \ddagger}$ & 1 & 4 & 22 & 38 & in \\
\hline LE 4-104 & 4 & V79 & (6) & 3 & $\mathrm{D} 21 / 9$ & 4 & 3 & 24 & 45 & in \\
\hline LE 4-8 & 4 & V79 & (4) & & D21/7-D23/7 & 1 & 4 & 24 & 45 & in \\
\hline LE 4-34 & 4 & V79 & (10) & 3 & $\mathrm{D} 21 / 9$ & 4 & 3 & 24 & 45 & in \\
\hline LE 4-56 & 4 & V79 & $(2)$ & 2 & D21/05 & 5 & 5 & 30 & 54 & in \\
\hline LE 4-105 & 4 & $4-39$ & (5) & 9 & DN4-DXP'1 & 7 & 3 & 38 & 66 & in \\
\hline LE 4-19 & 4 & $4-34$ & (1) & 3 & DLR2 & 9 & 6 & 42 & 66 & in \\
\hline LE 5-3 & 5 & VH32 & (4) & 1 & DLR5 $^{\ddagger \ddagger-D L R 2 ~}$ & 1 & 4 & 20 & 33 & in \\
\hline LE 5-11 & 5 & VH32 & (1) & 2 & DXP4-DHFL16 & & 6 & 25 & 57 & in \\
\hline LE 5-7 & 5 & VH32 & (1) & 4 & ${ }^{\ddagger \pm}$ DK $4^{\ddagger \pm}$-DK4 & 1 & 4 & 28 & 46 & out \\
\hline LE 5-2 & 5 & $5-51$ & $(0)$ & 5 & D21/10-DM1 & 7 & 3 & 31 & 51 & in \\
\hline LE 6-14 & 6 & $6-1$ & (1) & 4 & $\mathrm{DM}^{\ddagger \ddagger}$ & & 4 & 10 & 27 & in \\
\hline RS 6-91 & 6 & $6-1$ & $(0)$ & 4 & DN1 & 6 & 6 & 21 & 48 & in \\
\hline RS 6-21 & 6 & $6-1$ & (2) & 1 & D21/9-D21/7 & 1 & 4 & 23 & 39 & in \\
\hline LE 6-16 & 6 & $6-1$ & (2) & & DLR2 ${ }^{\ddagger}$-DN1-D22/12 & & 6 & 28 & 57 & in \\
\hline LE 6-1 & & $6-1$ & $(0)$ & 3 & $\mathrm{D} 21 / 7$ & 5 & 6 & 36 & 69 & in \\
\hline RS 39 & & oartial & & 2 & DM1-DLR3 ${ }^{\#}$ & & 6 & 17 & & \\
\hline RS 54 & D. & & & & DHQ52-DLR3 & & 4 & 22 & & \\
\hline RS 51 & & partial & & & D21/9-DM2 & & 4 & 32 & & \\
\hline RS 12 & & partial & & 12 & DLR1-DK1 & 10 & 6 & 40 & & \\
\hline
\end{tabular}

* Sequences are grouped according to the $\mathrm{VH}$ families.

${ }^{\ddagger}$ All germline gene sequences are taken from references 35 and 36 except V11 and V79 taken from reference 37 and VH32 taken from reference 38.

Number of mutations from the corresponding germline genes.

"Number of nucleotides in $\mathrm{N}$ region.

'Length of CDR3 was taken from residue 93 of the VH to the position preceding the TGG codon of the JH.

** I, in frame (in); and $O$, out of frame (out).

\# $\mathrm{D}$ germline gene used in reverse orientation.

VH family could not be assigned due to partial sequences. 


\begin{tabular}{|c|c|c|c|c|c|c|}
\hline & VH & $\mathbf{N}$ & D & $\mathbf{N}$ & $\mathrm{JH}$ & \\
\hline RS $1-103$ & TGTGCGGGA & & TGGCGTG & & ATGCTTTTGATATCTGG & $J 13$ \\
\hline LE $1-17$ & TGTGCGAGAGA & & GGGGTTGG & & ATGCTTTTGATATCTGG & \\
\hline RS $1-92$ & TGTGCGAGAGA & IAGGTGGC & CTGGGGA & CG & ATGCTTTTGATATCTGG & \\
\hline LE 4-89 & TGTGCGAGAGA & & GGGCAGTGTCAAACCCCATG & & ATGCTTTTGATATCTGG & \\
\hline LE 4-104 & TGTGCGAGAA & CAC & ACTATGATAGTAGTGGT & CTTG & ATGCTTTTGATATCTGG & \\
\hline LE 4-34 & TGTGCGAGAA & CAC & ACTATGATAGTAGTGGT & CTTG & ATGCTTTTGATATCTGG & \\
\hline LE $4-105$ & TGTGCGAGAGA & ICTAGAGGG & GGAGAACGTCCTACTATGGCTC & CAAGATG & ATGCCTTTGATATCTGG & \\
\hline LE $5-2$ & TGTGCGAGA & CGTCC & TTTGGGGGACTGGAACTAC & GGGGAAG & ATGCTTTTGATATCTGG & \\
\hline LE 3-15 & TGTGCGAGAGG & AGTGGACCGAT & TTACTATGATAGTATTGGT & CTCCG & GCTTTTGATATCTGG & \\
\hline LE $1-25$ & TGTGCGAGAGA & TGACTACG & CCGCA & & TTTGATATCTGG & \\
\hline LE $1-54$ & TGTGCGAGAGA & TGACTACG & CCGCA & & CTTGATATCTGG & \\
\hline LE $1-10$ & TGTGCGAGAGA & TGACTACG & CCGCA & & TTTGATATCTGG & \\
\hline LE $4-103$ & TGTGCGAGAA & CAC & ACTATGATAGTAGTGGTT & & & \\
\hline LE $1-76$ & TGTGCGAGA & & ATACCCCGTATTAGCAGTGGCTGGTTGGGGG & & ACTACTTTGACTACTGG & งมn \\
\hline RS 54 & & & CTAACTGGGGATTTGTGATGGT & & ACTACTTTGACTACTGG & \\
\hline RS 51 & & & GTATTACTATGATAGTAGTGGTACCCGAAATA & & ACTACTTTGACTACTGG & \\
\hline LE $4-8$ & TGTGCGAGAGA & & TTCGGGATTTTTGGAGTGGTTAT & c & CTACTTTGACTACTGG & \\
\hline RS $3-128$ & TGTGCGAAAGA & $\mathbf{x C}$ & ATATAGCGGGAGCTACT & & TACTTTGACTACTGG & \\
\hline LE 5-7 & TGTGCGAGA & TCGG & ACCTATGGCCGATACAGCTATGG & $\mathbf{A}$ & TACTTTGACTACTGG & \\
\hline LE $3-12$ & TGTGCGAAAC & & GGGGACTTATAGCAGTGGCTGGTTT & & CTTTGACTACTGG & \\
\hline LE 3-11 & & & & & & \\
\hline LE $3-20$ & TGTGCGAAAC & GGGACG & TTGCAGCAGTGGCTGG & $\cos$ & CTTTGACTACTGG & \\
\hline LE $6-14$ & TGTGCAAGAGG & Crea & CCAGTT & & TTTGACTACTGG & \\
\hline LE $1-100$ & TGTGCGAGAGA & TGACTACG & CCGCA & & TTTGACTACTGG & \\
\hline LE 4-63 & TGTGCGAGAAA & CTC & CCTGGGCTGCTGCTGGGC & $\boldsymbol{\lambda}$ & TTGACTACTGG & \\
\hline LE $3-21$ & TGTGCGAGAGA & $c 6$ & CTCCCCGAACTGGGGA & TTGTTG & TTGACTACTGG & \\
\hline LE 3-16 & TGTGTGAAAGA & TTAC & TACGATTTTTGGAGTGGTTAT & G & TTGACTACTGG & \\
\hline RS 6-21 & TGTGCAAGAGA & $\mathbf{\lambda}$ & TACTATGATAGTCTCGGGGTG & G & TTGACTACTGG & \\
\hline LE 5-3 & TGTGCGAGA & c & AAGAAGTACCAGCTGCCA & $\boldsymbol{\lambda}$ & TGACTACTGG & \\
\hline LE $1-9$ & TGTGCGAGAG & GTAAACCC & TATATC & & GACTACTGG & \\
\hline LE $1-29$ & TGTGCGAAAG & GTT & CTCAGTG & GCTGGTACTA & GACTACTGG & \\
\hline IE $4-56$ & TGTGCGAGAA & $\mathrm{cc}$ & TACGATATTTTGACTGGTTATTA & CCAGT & ACAACTGGTTCGACCCCTGG & J:5 \\
\hline LE $4-30$ & TGTGCGAGAAA & GGC & TGGTACCCC & & CAACTGETTCGACCCCTGG & \\
\hline LE 5-11 & TGTGCGAGA & $C A$ & GTATTACGATTTTTTCCAGCCGG & & ACTACTACTACTACGGTATGGACGTCTGG & J16 \\
\hline LE $6-1$ & TGTGCAAGAGA & ICG & TTACTATGTTCGGGGGAGTTATTATAAC & TCTCG & CTACTACTACTACGGTATGGACGTCTGG & \\
\hline LE $4-5$ & TGTGCGAGAG & G & GTCGCCGGGGG & & ACTACTACTACGGTATGGACGTCTGG & \\
\hline LE $1-42$ & TGTGCGAGAGA & ICTTTT & ATGCAGTGGCTGCG & & ACTACTACTACGGTATGGACGTTTGG & \\
\hline RS 12 & TGTGCAAGA & GATCCCCGGGTA & GGTGGTGTAGCAGTGGCT & GGGACCTCTG & ACTACCACTACGGTATGGACATCTGG & \\
\hline LE $1-6$ & TGTGCGAGGGA & & & & СTACTACTACGGTATGGACGTCTGG & \\
\hline RS 6-91 & TGTGCAAGA & TGGT & CAGCAGCTGGT CCGGGT & & TACTACTACGGTATGGACGTCTGG & \\
\hline LE $6-16$ & TGTGCAAGAGG & & AGCTCGCACCGGGTATAGCATTGGGACT & & TACTACTACGCTATGGACGTCTGG & \\
\hline LE $4-19$ & TGTGCGAGA & $\operatorname{rec}$ & GGATATTGTAGTGGTGGTAGCTGCTACTCC & CETCCGTGG & TACTACGGTATGGACGTCTGG & \\
\hline LE 3-13 & TGTGCGGGCGG & CTACGGT & G & & ACTACAGTATGGACGTCTGG & \\
\hline LE $1-82$ & TGTGCGAGAGA & AG & TAGCAGTGTC & TGGTTC & CTACGGTATGGATGTCTGG & \\
\hline RS 39 & & GG & GGTATAACTACCACA & & TACGGTATGGACGTCTGG & \\
\hline LE $3-1$ & TGTGCGAGAGA & & AAAG & & ATGGACGTCTGG & \\
\hline LE $3-2$ & TGTGCGAGAGA & & AAAG & & ATGGACGTCTGG & \\
\hline
\end{tabular}

Figure 3. Sequences of XLA-derived transcripts encompassing the CDR3 regions. Data are ordered by decreasing sizes of the various JH family segments. Possible residues for P diversity (39) are bolded. Putative N diversity at the D-D junctions is underlined. 
Rs 1-103

D23/7

Is: 1-17

DIR*

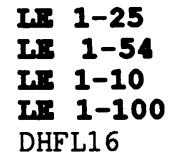

I. 1-9

DHFL16

RS. 1-92

DHQ52

IF 1-82

DK4*

DM2*

II. 1-29

DIR1

DLR4*

IE 1-42

DK1

IS: 1-76

DIR1

D23/7

DK1

DXP' 1

I. 3-13

DK1

Rs 3-128

DK4

D21/7

II. 3-21

D21/7*

DHQ52

I. 3-12

D21/7

DIR1 *

I. $3-11$

I. 3-20

DN1

D21/05

I. 3-16

DXP4

I. 3-15

D21/9

IT 4-5

DHFL16

I. $4-30$

DHFL16

I. $4-103$

D21/9

I. $4-63$

DIR1 *
TGGCGTG

gtattagcattttTGGaGTGgttattatacc

GGGGTTGG

ggggcctcctgggtgGGGGCTGGgcttgtggg

TGACTACGCCGCA

TGACTACGCCGCA

TGACTACGCCGCA

TGACTACGCCGCA

TGtCTACGgtgtaatcccaccggtt

GTAAACCCTATATC

tgtctacggtgGTAAtCCCaccggtt

TAGGTGGGCTGGGGACG

tt AaCTGGGGA

AGTAGCAGTGTCTGGTTC
gtaaccaTAGCtGTaTCcac
gTGGTTCcggttatacc

GTTCTCAGTGGCTGGTACTA

... . acgagccacagcCTCAGaGccctgaagga.........

ggcatagcaGCTGGTACTACtacaatatcct

TCTTTTATGCAGTGGCTGCG

gtggATaCAGTGGCTaCGattac

ATACCCCGTATTAGCAGTGGCTGGTTGGGGG

.... gcccetgaaggAgACCCCGcccacaagccc.... .

GTATTAGCAtttttggaggtggttattatacc

gtggataCAGTGGCTacgattac

gtattactaTGGTTCGGGGagt tat tacaac

CTACGGTG

gtggatacagtggCTACGaTtac

CATATAGCGGGAGCTACT

gtggATACAGCtatggttac

gtattactatgttcgGGGAGtTAtTataac

CGCTCCCCGAACTGGGGATTGTTG

gttaTAATAACTCCCCGAACatagtaatac ttAACTGGGGA

GGGGACTTATAGCAGTGGCTGGTTT

gtattactatgttcGGGGAgTTAT tataac gctctgagGCtGTGGCTCGTTTtaggtgtgggg

GGGACGTTGCAGCAGTGGCTGGCGG

GGGACGTTGCAGCAGTGGCTGGCGG

gggtaTaGCAGCAGctggtac

gtattacgatatttTGaCTGGttattataac

TTACTACGATTTTTGGAGTGGTTATG

gtat TACGATTTTTGGAGTGGTTAT tatacc

AGTGGACCGATTTACTATGATAGTAGTGGTCTCCG gt aTTACTATGATAGTAGTGGTtattactac

GGTCGCCGGGGG

tGTCtaCGGtGGtaatcccaccggtt

GGCTGGTACCCC

tgtctacggTGGTAatCCcaccggtt

CACACTATGATAGTAGTGGTT

gtattACTATGATAGTAGTGGTTat tactac

CTCCCTGGGCTGCTGCTGGGCA

. . . . cCtCCTGGGtCGggGCTGGGCttgtgggcgggg. . . .
Figure 4. Identification of D germline genes from which transcripts originate. Portions of germline genes encountered in transcripts are underlined. Identities appear in upper cases, differences in lower cases. *Usage of germline gene in reverse orientation. Germline sequences are taken from references $40-43$. 


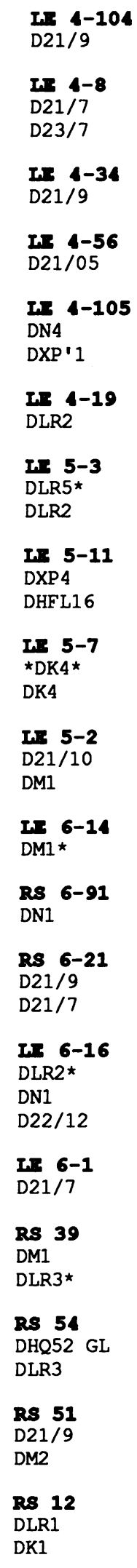

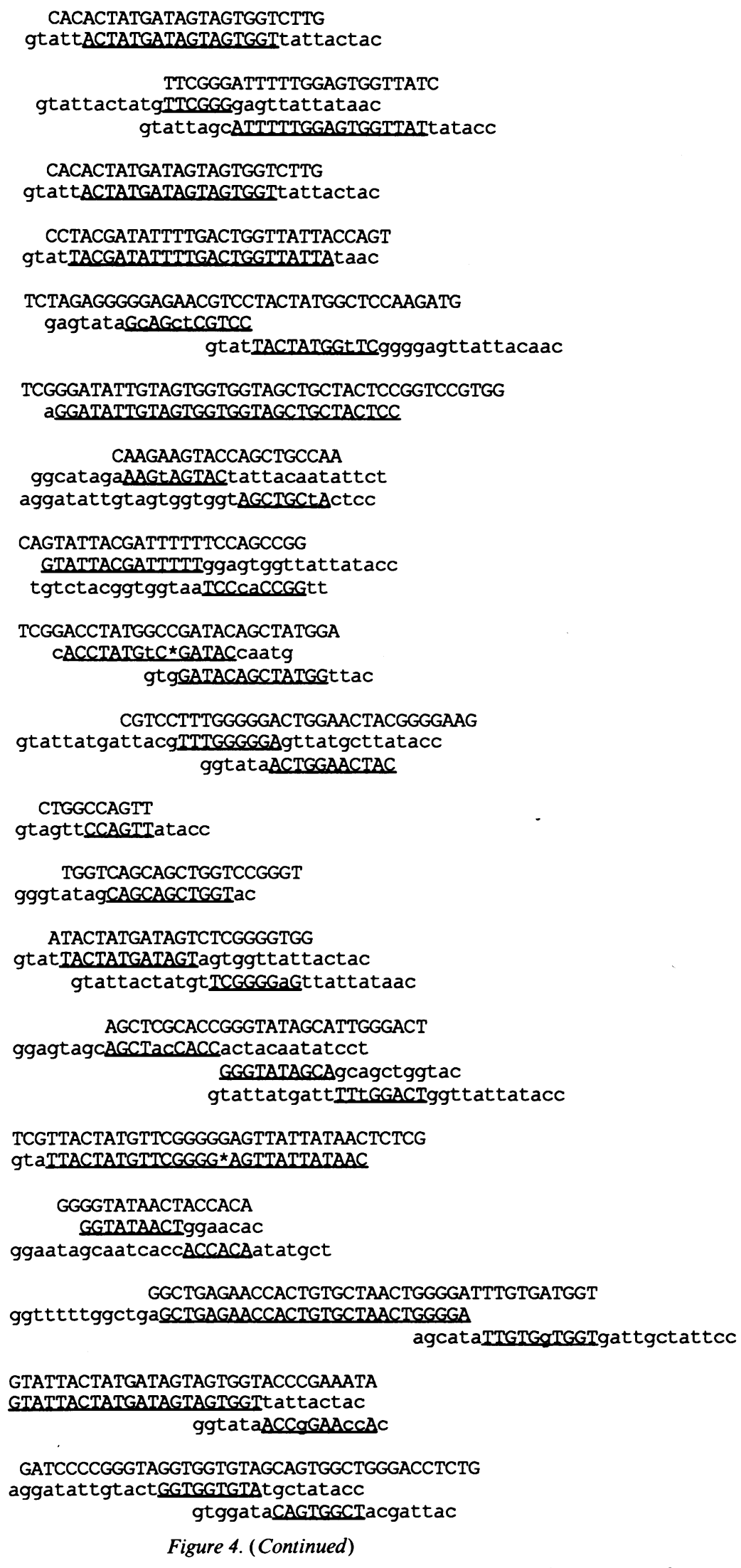

Figure 4. (Continued)

nucleotides and did not exceed 12. It cannot be excluded that the largest $\mathrm{N}$ regions might be encoded by so far undescribed $\mathrm{D}$ genes. In addition, possible $\mathrm{N}$ diversity (underlined residues in Fig. 3) could be defined at some D-D junctions, although very

limited both in number (five cases) and size (one nucleotide). Length of the N-D-N segments extended from 0 to 42 nucleotides, with an average of 20-25 (Fig. 3 and Table I).

$\mathrm{JH}$ regions were found encoded by $\mathrm{JH} 3$ to $\mathrm{JH} 6$ genes, with 


\begin{tabular}{|c|c|c|c|c|c|c|c|c|}
\hline & \multicolumn{3}{|c|}{ Direct* } & \multicolumn{3}{|c|}{ Reverse $^{\ddagger}$} & \multirow[b]{2}{*}{ Gene usage } & \multirow[b]{2}{*}{ Family usagell } \\
\hline & 1st & 2 nd & 3 rd & 1 st & 2nd & $3 \mathrm{rd}$ & & \\
\hline & & & & & & & $\%$ & $\%$ \\
\hline 1. DXP $(32 \%)$ & & & & & & & & 38 \\
\hline $\mathrm{D} 21 / 9$ & & 3 & & & & & 6 & \\
\hline $\mathrm{D} 21 / 10$ & 1 & & & & & 1 & 4 & \\
\hline $\mathrm{D} 21 / 7$ & 1 & 2 & 1 & 1 & & & 10 & \\
\hline D21/05 & & 2 & & & & & 4 & \\
\hline $\mathrm{D} 23 / 7$ & 1 & & 1 & & & & 4 & \\
\hline D22/12 & & 1 & & & & & 2 & \\
\hline DXP4 & & 2 & & & & & 4 & \\
\hline $\mathrm{DXP}^{\prime} 1$ & 2 & & & & & & 4 & \\
\hline 2. DLR $(20 \%)$ & & & & & & & & 14 \\
\hline D5 & & & & & 1 & & 2 & \\
\hline D4 & & & & & 1 & & 2 & \\
\hline \multicolumn{9}{|l|}{ D3 } \\
\hline D2 & & 1 & 1 & 1 & & & 6 & \\
\hline D1 & & 1 & & & 1 & & 4 & \\
\hline 3. DA $(12 \%)$ & & & & & & & & 2 \\
\hline \multicolumn{9}{|l|}{ DA1 } \\
\hline DA4 & & & & 1 & & & 2 & \\
\hline 4. DK $(8 \%)$ & & & & & & & & 10 \\
\hline DK1 & 1 & & 3 & & & & 8 & \\
\hline DK4 & & & & 1 & & & 2 & \\
\hline 5. DN (8\%) & & & & & & & & 8 \\
\hline DN1 & 1 & 2 & & & & & 6 & \\
\hline DN4 & & & 1 & & & & 2 & \\
\hline 6. DM $(8 \%)$ & & & & & & & & 6 \\
\hline DM2 & & & & & 1 & & 2 & \\
\hline DM1 & & & 1 & 1 & & & 4 & \\
\hline 7. DFL16 (4\%) & & 3 & 2 & & & & 10 & 10 \\
\hline 8. DHQ52 (4\%) & 1 & & & & & & 2 & 2 \\
\hline 9. DIR (8\%) & & & & & & & & 10 \\
\hline DIR 1 or DIR2 & & 2 & & 1 & 1 & 1 & 10 & \\
\hline Total & 8 & 19 & 10 & 6 & 5 & 2 & & \\
\hline
\end{tabular}

Numbers in parentheses represent the expected frequency of utilization according to the size of each family. Individual genes within each family are listed from top to bottom according to their physical proximity to the JH locus. 1st, 2nd, and 3rd refer to the three reading frames.

D gene references are from references $40-43$.

* $\mathrm{D}$ gene in direct orientation.

${ }^{\ddagger} \mathrm{D}$ gene in reverse orientation.

${ }^{\S}$ Frequency of gene usage of D segments in direct and reverse orientation.

"Frequency of D family usage.

various degrees of truncation of the 5 ' ends (Fig. 3). Clone LE 4-103 was extensively truncated containing only the four last $\mathrm{JH}$ codons. Allelic variants used were $\mathrm{JH} 3 \mathrm{~b}, \mathrm{JH} 4 \mathrm{~b}, \mathrm{JH} 5 \mathrm{~b}$, JH6b, and JH6c (44). Occasional mutations (one or two) were observed in $27 \%$ of the analyzed sequences.

CDR3 segments were defined from residue 93 of the $\mathrm{VH}$ (numbering of Kabat et al. [45]) to the position preceding the TGG codon of the JH genes. On this basis the CDR3 length varied from 21 to 69 , with an average value of 41 (Table I).

Of the VDJ sequences $88 \%$ had an open reading frame ( Table I). Although most V-D-J associations could be considered random, several peculiar cases were observed. For instance, the same V-D combination was found associated to different $\mathrm{JH}$ (LE 1-100 and LE 1-25). Conversely the same DJ was found associated to discrete VHs (LE 1-10 and LE 1-25; LE 4-34 and
LE 4-104). Finally, two VDJ were using two discrete leader segments (LE 1-54 and LE 1-25). A few sequences were truncated, (LE 1-23 lacking DJ, LE 4-103 lacking most of the 5' JH codons), or contained multiple deletions in VH (LE 3-11).

Expression of $\kappa$ transcripts. $\kappa$ transcripts could be identified in patient L.E.'s bone marrow cells after PCR using primers covering the four $\mathrm{V}_{\kappa}$ families and the 5 ' end of $\mathrm{C}_{\kappa}$. Bands of the expected size (between 320 and $340 \mathrm{bp}$, depending upon the $V_{K}$ families) were clearly detected, although of fainter intensity as compared to normal bone marrow cells (Fig. 5).

\section{Discussion}

The expression of Ig and pre-B specific-Ig-related genes was analyzed in bone marrow cells derived from two patients with a 


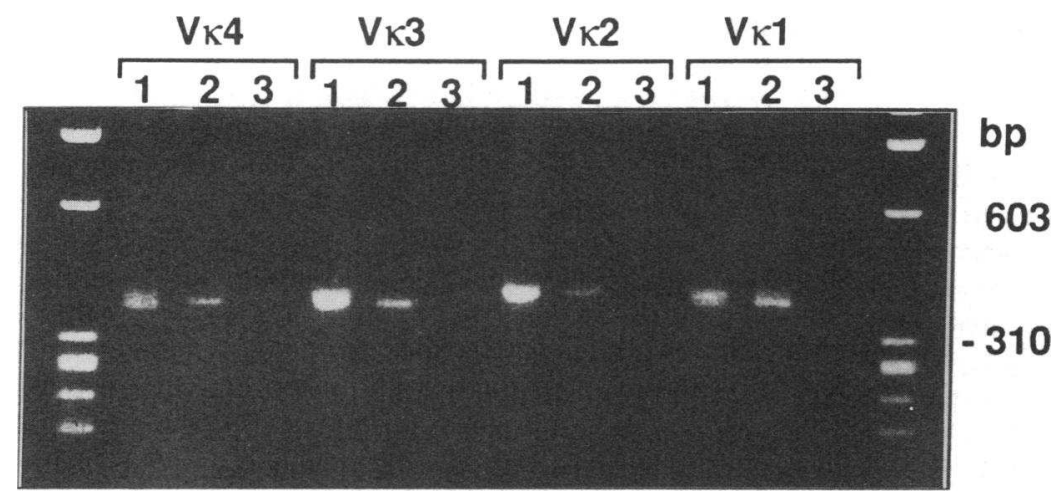

Figure 5. Expression of $\mathrm{V}_{\kappa}$ gene families in XLA and normal bone marrow cells, by PCR analysis, using $500 \mathrm{ng}$ of RNA. PCR products were detected after electrophoresis on $2 \%$ agarose gel by ethidium bromide staining. Sizes were estimated from the $\Phi$ X174 -Hae III fragments. Lanes 1 , normal bone marrow; Lanes 2, XLA bone marrow; Lanes 3, no input RNA. severe form of XLA. FACS analysis pointed to the pre-B nature of cells of the B lineage as appreciated from the absence of mIgM and of the CD21 and CD24 markers, characteristic of the $\mathrm{B}$ lymphocytes and the proportion of $\mathrm{C} \mu$-positive cells that were found within normal limits. The presence of pre-B cells was confirmed through the expression of CD19 and/or CD22 in one third of the cells, of which $66 \%$ were also positive for CD34 (46). Double positive in normal bone marrow were only $14 \%$, which is suggestive of a differentiation block somewhere along the pro-B $\rightarrow$ pre-B pathway.

Because some critical step necessary to the pre-B $\rightarrow$ B transition may be triggered by the $\mu-\psi \mathrm{L}$ complex $(24,47,48)$, we first analyzed the expression of pre-B specific genes. Transcripts of the Ig-related genes, $\lambda$-like and V Pre-B, were identified by PCR, yielding fragments of the expected sizes (Fig. 2) and expressed in amounts that were similar to normal bone marrow. This indicates that pre-B cell differentiation can go along although the higher proportion of CD34-positive cells suggests a progressive decline in that process.

We next turned to $\mu$ chain expression. Anchored PCR, using an oligonucleotide primer specific for the $5^{\prime}$ end of the $C \mu$ region revealed that most transcripts encompassed the $\mathrm{V}$ region (at least $66 \%$ ), whereas $11 \%$ were clearly of the D-J-C $\mu$ type. This already indicates that transcription is not limited to $\mathrm{D}_{\mu}(9)$ or of the more recently described LS-C $\mu$ transcripts (49). This finding prompted analysis of complete VDJ $(\mathrm{C} \mu)$ transcripts that were easily derived upon amplification with primers specific of the various VH-leader sequences and of the $\mathrm{C} \mu 5^{\prime}$ region. Detailed analysis of the $48 \mu$ transcripts (Table I) revealed that all characteristics of an early "pre-B" functional repertoire were indeed present:

All VH families were identified (except VH2), including a marked contribution of VH5 and VH6, $(50,51)$. It can be observed that VH gene usage was biased in several ways: $(a) 19$ genes accounted for the $\mathbf{4 8}$ discrete V-D-J transcripts, indicating that some genes were used with a high frequency (Table I); (b) 16 out of these 19 genes were located in the $800 \mathrm{~kb}$ region covering the $3^{\prime}$ end of the VH locus, as schematically presented in Fig. 6, according to the map recently published by Matsuda et al. (36); (c) In Fig. 6, it can also be observed that most of the genes used in XLA were also expressed in a fetal liver as early as 8-13 wk of gestation (52). A somewhat similar gene usage in

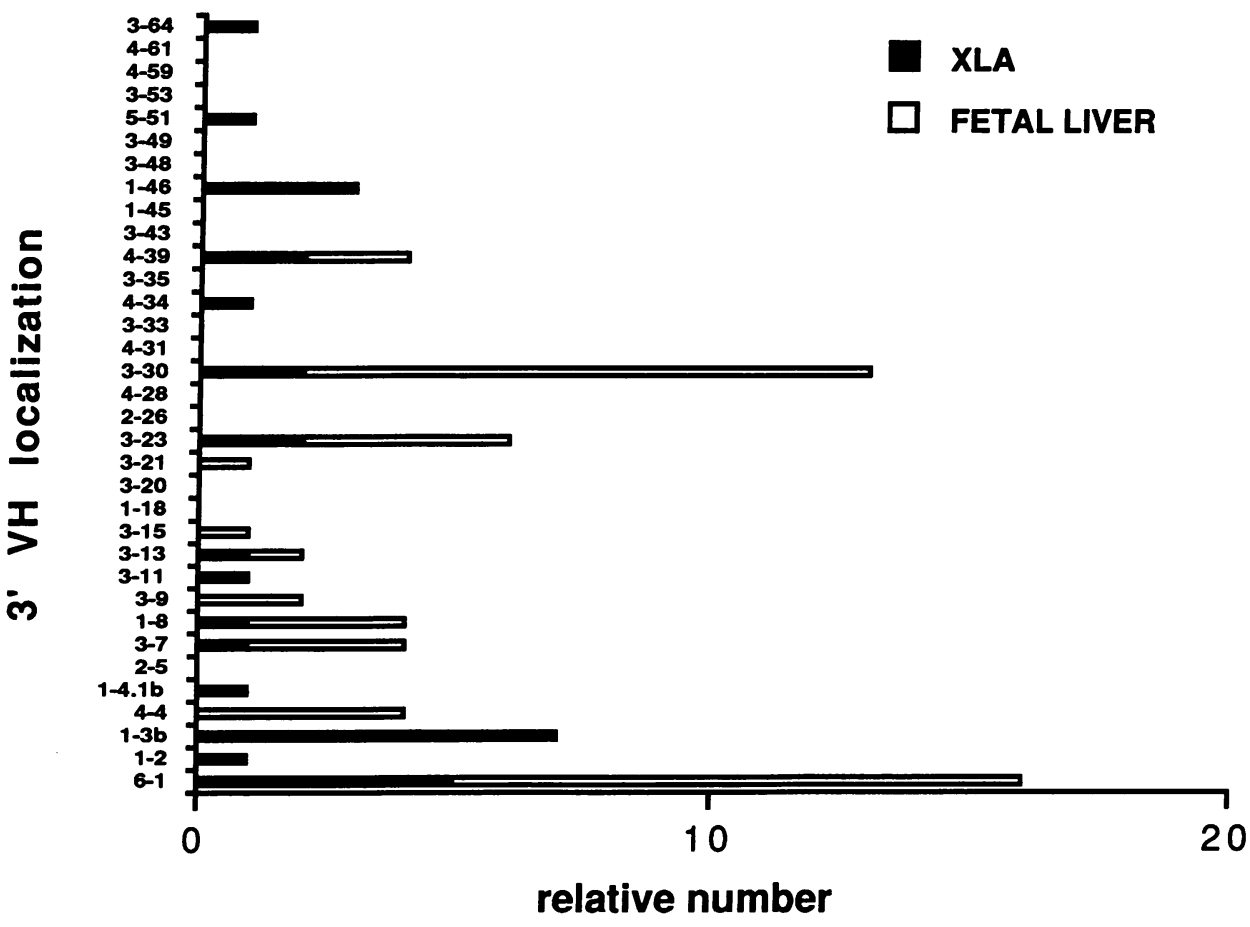

Figure 6. VH gene utilization in XLA bone marrow and fetal liver (52). Gene numbering (including functional genes only) on the $y$-axis is that of Matsuda et al. (36) and is presented from $5^{\prime}$ (top) to $3^{\prime}$ (bottom). Length of bars reflects the gene usage frequencies. 
human fetal liver can be derived from data obtained by Schroeder et al. $(53,54)$ at 15 or $18 \mathrm{wk}$ of gestation and is reminiscent of the preferential usage of the most $3^{\prime} \mathrm{VH}$ gene early in mice ontogeny (55-57).

As outlined in Fig. 7, the average size of the XLA-derived D segments was close to those of the fetal liver between 8 and 13 wk of gestation (52) and significantly shorter than those of their adult PBL counterparts $(44,58)$. Same conclusions could be drawn from the comparisons of CDR3, indicating that $\mathrm{D}$ and CDR3 lengths were well correlated. They were also found shorter than those reported by Timmers et al. (12), and Anker et al. (11) who studied the XLA repertoire in EBV-derived clones which were found closer to that of adult PBL (Fig. 7). Besides their distinctive lengths, the $\mathrm{D}$ regions described by Timmers et al. (12) do not differ from the other characteristics described in this paper. Our data indicate that $53 \%$ of the XLA D sequences involved D-D fusions using up to four germline D segments. The way they originate through multiple $\mathrm{D}$ fusions seems a general process of generating diversity in the $\mathrm{D}$ region, both in XLA and normal B cells (58). The reference based on $10 \%$ of D-D fusion for the adult PBL suggested by Yamada et al. (44) is in fact misleading for comparison, since these authors did not take inverted and DIR sequences into account in their conclusions.

A large variety of D segments was identified, including DIR genes, either in direct or reverse orientation. In fact, as it can be seen in table II, no particular pattern emerges in the D usage, which grossly reflects the estimated gene number. In this regard, the largest DXP family is also the most represented in XLA, but also in other physiological situations (58). By contrast, we did not observe the increased expression of DHQ52 that was reported in fetal liver (58). Finally, analysis of the reading frame usage revealed that all three frames were used, eventhough RF2 was found in a twofold excess. This observation is in sharp contrast with the situation depicted in the mouse, in which RF1 is largely overused, as the result of a strong selection process (59).

$\mathrm{JH}$ gene usage also reveals that the expression pattern of the XLA repertoire is close to that of the fetal liver (Fig. 8), with a major contribution of $\mathrm{JH} 3$ (which is only weakly represented in the adult repertoire), $\mathrm{JH} 4$ and JH6. Contribution of $\mathrm{JH}$ genes could vary in length, due to various truncations, especially for JH6, in agreement with previous reports (44).

$\mathrm{N}$ diversity (with possible examples of $\mathrm{P}$ diversity, see fig. 3 ) occurred on both V-D and D-J sides, and remained very limited, bringing another criteria of earliness $(60,61)$. It should be noted however that assignment of $\mathrm{N}$ regions remains partially questionable, in that they are defined in a negative way, from the absence of known germline gene counterpart. Undefined D genes may therefore lead to overweight contribution of $\mathrm{N}$ diversity.

Finally, random somatic mutations were present in limited extent on VH, D and JH, as can be expected for an early repertoire (60).

Thus, by all the analyzed criteria, the XLA repertoire resembles that of the normal fetal lymphopoietic tissues, suggestive of a typical pre-B phenotype. These results are in agreement with previous phenotypic characterization of the bone marrow cell population in XLA patients $(62,63)$. By contrast to other reports $(3,9,49,64)$, our data indicate that rearrangement mechanisms seem fully functional, although a possible decrease in efficiency of the pro-B to pre-B transition, as followed by the DJ to VDJ rearrangement cannot be quantitatively as-
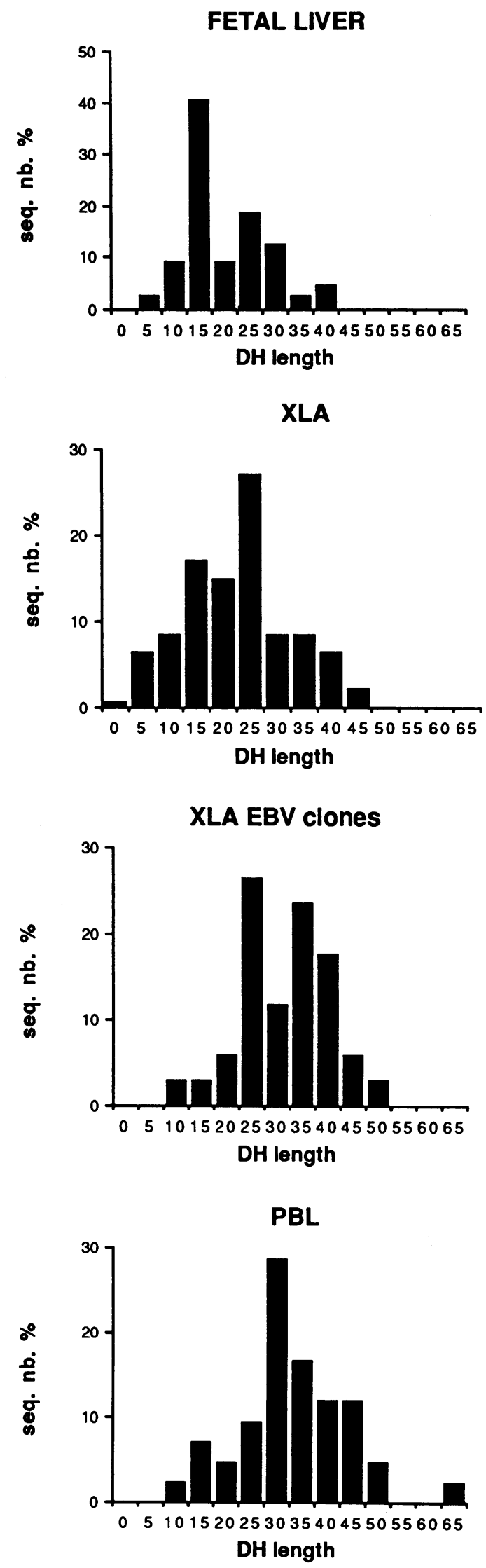

Figure 7. Length pattern of the D usage in XLA bone marrow cell transcripts (this work) compared to fetal liver (52), XLA-derived EBV clones (11-13), and normal adult PBL (44). Computed sequences cover N-D-N regions. 

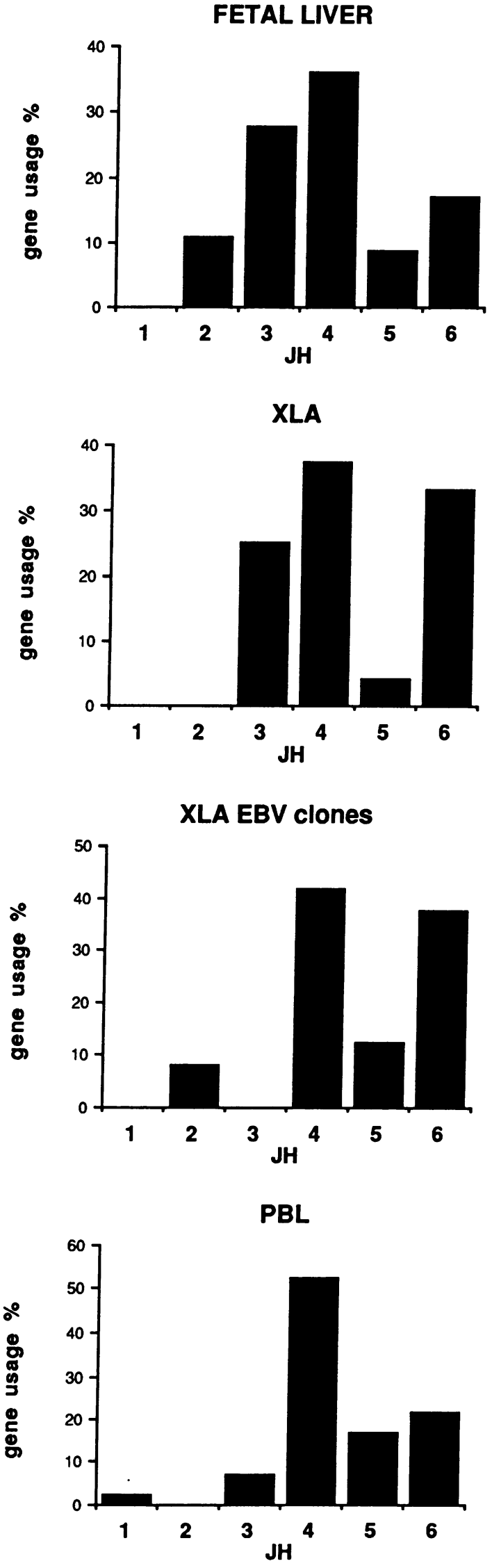

Figure 8. JH gene usage in XLA bone marrow cell transcripts (this work) compared to fetal liver (52), XLA-derived EBV clones (1113), and normal adult PBL (44). sessed from our data. These conflicting results might be reconciled by considering the XLA defect as a pleiotropic mechanism leading to a decrease in the efficiency of discrete steps of the early development of the B lineage, thus resulting in different phenotypes based on the severity of the disease. In addition, it can also be stressed that $88 \%$ of the transcripts had an open reading frame, imposing evidence that a selective process must operate at the pre-B stage. As the $\mu$ chains are associated with $\lambda$-like and V Pre-B gene products, the $\mu-\psi \mathrm{L}$ chain complex may already be actively involved in the acquisition and expansion of a pre-B specific repertoire that may condition the shaping of the mature HL receptors. In XLA cells, all steps leading to the shaping of the pre-B repertoire appear therefore functional. Preferential localization of the expressed $\mathrm{VH}$ genes to the most $3^{\prime}$ portion of the IGVH locus still raises the possibility that extension of the $\mathrm{VH}$ repertoire to the entire locus remains partially hindered. This may be in line with recent reports that discrete regulation of the $3^{\prime}$ vs $5^{\prime} \mathrm{VH}$ usage operates in the mouse: $(a)$ in mice transgenic for a human $\mu$ gene, endogenous V-D-J rearrangement was blocked except for the most $3^{\prime}$ VH $(65)$ and $(b)$ conversely, in Xid mice (66), another X-linked defect, preferential usage of the most $3^{\prime} \mathrm{VH}$ is altered in ontogeny.

Our analysis performed on XLA bone marrow cells provides direct access to the pre-B cell repertoire which is truly representative of the defect. Analysis of EBV clones derived from XLA patients may therefore contain a bias linked to the selection of a minor population of $B$ cells that have escaped the XLA defect $(11,12)$. The leakiness of XLA has been previously substantiated, and may be more or less important, in conjunction with the severity of the disease $(7,67,68)$. In this context, the presence of $\kappa$ transcripts in noticeable amounts in our samples indicate that some degree of leakiness has indeed taken place allowing the system a limited progression in the B cell differentiation pathway.

\section{Acknowledgments}

We express our deep gratitude to Dr. Honjo and colleagues for making available to us their manuscript in press in Nature Genetics. We also thank Drs. Cécile Tonnelle and Anne-Marie Cuisinier (Centre d'Immunologie de Marseille-Luminy [CIML]) for making their preprint available and for fruitful discussions. We also acknowledge expert technical assistance of Mrs. Elise Termine (CIML) and generous gift of DNA probes from Drs. F. Alt, J. Berman (University of Maryland, Baltimore), T. Honjo, M.-P. Lefranc (University of Montpellier, France), and P. Leder (Harvard Medical School, Boston).

This work was supported by CNRS, INSERM, Ministère de la Recherche et de l'Espace, and Association de la Recherche contre le Cancer.

\section{References}

1. Cooper, M., and J. L. Butler. 1989. Primary immunodeficiency diseases. In Fundamental Immunology. W. Paul, editor. Raven Press, New York. 10331057.

2. De Saint Basile, G., and A. Fischer. 1991. X-linked immunodeficiencies: clues to genes involved in T-and B-cell differentiation. Immunol. Today. 12:456461.

3. Mensink, E., R. Schuurman, J. Schot, A. Thompson, and F. W. Alt. 1986. Immunoglobulin heavy chain rearrangements in X-linked agammaglobulinemia. Eur. J. Immunol. 16:963-967.

4. Schwaber, J., J. Payne, and R. Chen. 1988. B lymphocytes from X-linked agammaglobulinemia: delayed expression of light chain and demonstration of lyonization in carriers. J. Clin. Invest. 81:514-522.

5. Fearon, E. R., J. A. Winkelstein, C. I. Civin, D. M. Pardoll, and B. Vogel- 
stein. 1987. Carrier detection in XLA by analysis of X-chromosome inactivation N. Engl. J. Med. 316:427-431.

6. Conley, M. E., P. Brown, A. R. Pickard, R. H. Buckley, D. S. Miller, W. H. Raskind, J. W. Singer, and P. G. Fialkow. 1986. Expression of the gene defect in X-linked agammaglobulinemia. N. Engl. J. Med. 315:564-567.

7. Hendriks, R. W., and R. K. B. Schuurman. 1991. Genetic of human Xlinked immunodeficiency diseases. Clin. Exp. Immunol. 85:182-192.

8. Campana, D., J. Farrant, N. Inamidar, D. B. Webster, and G. Janossy. 1990. Phenotypic features and proliferative activity of B cell progenitors in Xlinked agammaglobulinemia. J. Immunol. 145:1675-1680.

9. Schwaber, J., H. Molgaard, S. H. Orkin, J. H. Gould, and F. S. Rosen. 1983. Early pre-B from normal and X-linked agammaglobulinemia produce C-mu without attached VH region. Nature (Lond.). 304:355-358.

10. Levitt, D., H. Ochs, and R. Wedgwood. 1984. Epstein-Barr virus induced lymphoid cell lines derived from the peripheral blood of patients with $\mathrm{X}$-linked agammaglobulinemia can secrete IgM. J. Clin. Immunol. 4:143-150.

11. Anker, R., M. E. Conley, and B. A. Pollok. 1989. Clonal diversity in the B cell repertoire of patients with X-linked agammaglobulinemia. J. Exp. Med. 169:2109-2119.

12. Timmers, E., M. Kenter, A. Thompson, M. E. M. Kraakman, J. E. Berman, F. W. Alt, and R. K. B. Schuurman. 1991. Diversity of immunoglobulin heavy chain gene segment rearrangement in B lymphoblastoid cell lines from $\mathrm{X}$-linked agammaglobulinemia patients. Eur. J. Immunol. 21:2355-2363.

13. Mortari, F., H. D. Ochs, R. J. P. Wedgwood, and H. W. Schroeder, Jr. 1991. Immunoglobulin variable heavy chain $\mathrm{CDNA}$ sequence from a patient with X-linked agammaglobulinemia. Nucleic Acids Res. 19:673.

14. Alt, F. W., T. K. Blackwell, R. A. De Pinho, M. G. Reth, and M. D. Yancopoulos. 1986. Regulation of genome rearrangement events during lymphocyte differenciation. Immunol. Rev. 89:5-30.

15. Nussenweig, M. C., A. C. Shaw, E. Sinn, D. B. Danner, K. L. Holmes, H. C. Morse, and P. Leder. 1987. Allelic exclusion in transgenic mice that expressed the membrane form of immunoglobulin $\mu$. Science (Wash. DC). 236:816-819.

16. Kitamura, D., J. Roes, R. Kühn, and K. Rajewsky. 1991. A B cell-deficient mouse by targeted disruption of the membrane exon of the immunoglobulin $\mu$ chain gene. Nature (Lond.). 350:423-426.

17. Kerr, W. G., M. D. Cooper, L. Feng, P. D. Burrows, and L. M. Hendershot. 1989. $\mu$ heavy chains can associate with a pseudo light chain complex ( $\Psi L$ ) in human pre-B cell lines. Int. Immunol. 1:355-361.

18. Hollis, G. F., R. J. Evans, J. M. Stafford-Hollis, S. J. Korsmeyer, and J. P. McKearn. 1989. Immunoglobulin lambda light-chain-related genes 14.1 and 16.1 are expressed in pre-B cells and may encode the human immunoglobulin omega light-chain protein. Proc. Natl. Acad. Sci. USA. 86:5552-5556.

19. Schiff, C., M. Milili, and M. Fougereau. 1989. Isolation of early immunoglobulin lambda-like gene transcripts in human fetal liver. Eur. J. Immunol. 19:1873-1878.

20. Schiff, C., M. Bensmana, P. Guglielmi, M. Milili, M.-P. Lefranc, and M Fougereau. 1990. The immunoglobulin $\lambda$-like gene cluster (14.1, 16.1 and F $\lambda 1)$ contains gene (s) selectively expressed in pre-B cells and is the human counterpart of the mouse $\lambda 5$ gene. Int. Immunol. 2:201-207.

21. Bossy, D., M. Milili, J. Zucman, G. Thomas, M. Fougereau, and C. Schiff. 1991. Organization and expression of the lambda-like genes that contribute to the mu-pseudo light chain complex in human pre-B cells. Int. Immunol. 3:10811090.

22. Bauer, S. R., A. Kudo, and F. Melchers. 1988. Structure and preB lymphocyte restricted expression of the VpreB gene in humans and conservation of its structure in other mammalian species. EMBO (Eur. Mol. Biol. Organ.) J. 7:111116.

23. Sambrook, J., E. F. Fritsh, and T. Maniatis. 1990. Molecular Cloning, 2nd edition. Cold Spring Harbor Laboratory Press, Cold Spring Harbor, NY.

24. Schiff, C., M. Milili, D. Bossy, A. Tabilio, F. Falzetti, J. Gabert, P. Mannoni, and M. Fougereau. 1991. $\lambda$-like and VpreB gene expression: an early B lineage marker of human leukemias. Blood. 78:1516-1525

25. Marks, J. D., M. Tristem, A. Karpas, and G. Winter. 1991. Oligonucleotide primers for polymerase chain reaction amplification of human immunoglobulin variable genes and design of family-specific oligonucleotide probes. Eur. $J$. Immunol. 21:985-991.

26. Loh, E. Y., J. F. Elliot, S. Cwirla, L. L. Lanier, and M. M. Davis. 1989. Polymerase chain reaction with single-sided specificity: analysis of $\mathrm{T}$ cell receptor $\delta$ chain. Science (Wash. DC). 243:217-220.

27. Dower, W. J., J. F. Miller, and C. W. Ragsdale. 1988. High efficiency transformation of E. coli by high voltage electroporation. Nucleic Acids Res. 16:6127-6130.

28. Sanger, F., S. Nicklen, and A. Coulson. 1977. DNA sequencing with chain-terminating inhibitors. Proc. Natl. Acad. Sci. USA. 74:5463-5467.

29. Dariavach, P., G. Lefranc, and M. P. Lefranc. 1987. Human immunoglobulin C lambda 6 gene encodes the Kern + Oz-lambda chain and C lambda 4 and C lambda 5 are pseudogenes. Proc. Natl. Acad. Sci. USA. 84:9074-9078.

30. Ravetch, J. V. 1981. Structure of human immunoglobulin mu locus:characterisation of embryonic and rearranged $\mathrm{J}$ and $\mathrm{D}$ genes. Cell. 27:583-591.

31. Hieter, P. A., E. E. Max, J. G. Seidman, J. V. Maizel, Jr., and P. Leder.
1980. Cloned human and mouse kappa immunoglobulin constant and $\mathrm{J}$ region genes conserve homology in functional segments. Cell. 22:197-207.

32. Kodaira, H., T. Kinashi, I. Umemura, F. Matsuda, T. Noma, Y. Ono, and T. Honjo. 1986. Organization and evolution of variable region genes of the human immunoglobulin heavy chain. J. Mol. Biol. 190:529-541.

33. Milili, M., M. Fougereau, P. Guglielmi, and C. Schiff. 1991. Early occurrence of immunoglobulin isotype switching in human fetal liver. Mol. Immunol. 28:753-761.

34. Berman, J. E., S. J. Mellis, R. Pollock, C. L. Smith, H. Suh, B. Heinke, C. Kowal, U. Surti, L. Chess, C. R. Cantor, and F. W. Alt. 1988. Content and organization of the human Ig VH locus: definition of three new VH families and linkage to the Ig CH locus. EMBO (Eur. Mol. Biol. Organ.) J. 7:727-738.

35. Shin, E. K., F. Matsuda, H. Nagaoka, Y. Fukita, T. Imai, K. Yokoyama, E. Soeda, and T. Honjo. 1991. Physical map of the 3' region of the human immunoglobulin heavy chain locus: clustering of autoantibody-related variable segments in one haplotype. EMBO (Eur. Mol. Biol. Organ.) J. 10:3641-3645.

36. Matsuda, F., E. K. Shin, H. Nagaoka, R. Matsumura, M. Haino, Y. Fukita, S. Taka-ishi, T. Imai, J. H. Riley, R. Anand, E. Soeda, and T. Honjo. 1992. Structure and physical mapping of 64 variable segments in the 3'0.8-megabase region of the human immunoglobulin heavy-chain locus. Nature Genet. 3:88-94.

37. Lee, K. H., F. Matsuda, T. Kinashi, M. Kodaira, and T. Honjo. 1987. A novel family of variable region genes of the human immunoglobulin heavy chain J. Mol. Biol. 195:761-768.

38. Pascual, V., and J. D. Capra. 1991. Human immunoglobulin heavy-chain variable region genes: Organization, polymorphism, and expression. $A d v$. Immunol. 49:1-64.

39. Lafaille, J. J., A. DeCloux, M. Bonneville, Y. Takagaki, and S. Tonegawa 1989. Junctional sequences of $T$ cell receptor gamma delta genes: implications for gamma delta $\mathrm{T}$ cell lineages and for a novel intermediate of V-(D)-J joining. Cell. 59:859-870.

40. Buluwela, L., D. G. Albertson, P. Sherrington, P. H. Rabbitts, N. Spurr, and T. H. Rabbitts. 1988. The use of chromosomal translocations to study human immunoglobulin gene organization: mapping DH segments within $35 \mathrm{~kb}$ of the $\mathrm{C}$ mu gene and identification of a new DH locus. EMBO (Eur. Mol. Biol. Organ.) J. 7:2003-2010.

41. Sonntag, D., B. Weingartner, and R. Grutzmann. 1989. A member of a novel human DH gene family: DHFL16. Nucleic Acids Res. 17:1267.

42. Zong, S. Q., S. Nakai, F. Matsuda, K. H. Lee, and T. Honjo. 1988. Human immunoglobulin D segments: isolation of a new D segment and polymorphic deletion of the D1 segment. Immunol. Lett. 17:329-333.

43. Ichihara, Y., H. Matsuoka, and Y. Kurosawa. 1988. Organization of human immunoglobulin heavy chain diversity gene loci. EMBO (Eur. Mol. Biol. Organ.) J. 13:4141-4150.

44. Yamada, M., R. Wasserman, B. A. Reichard, S. Shane, A. J. Caton, and G. Rovera. 1991. Preferential utilization of specific immunoglobulin heavy chain diversity and joining segments in adult human peripheral blood B lymphocytes. J. Exp. Med. 173:395-407.

45. Kabat, E. A., T. T. Wu, H. M. Perry, K. S. Gottesman, and C. Foeller. 1991. Sequences of Proteins of Immunological Interest. 5th edition. Volume 2 National Institutes of Health, Bethesda, MD. 1335-1343.

46. Ludwig, W. D., J. V. Teichmann, J. Harbott, C. R. Bartram, H. SeibtJung, A. Gatzke, S. Böttcher, and E. Thiel. 1989. Reactivity of acute mixed-lineage leukemias with the B-cell panel of $\mathrm{mAb}$ : correlation between immunophenotype and genotype. In Leucocyte typing IV. White Cell Differentiation Antigens W. Knapp, B. Dorken, W. R. Gilks, E. P. Rieber, R. E. Schmidt, H. Stein, and A. E. G. K. Von Dem Borne, editors. Oxford University Press., Oxford. 193-194.

47. Tsubata, T., and S. I. Nishikawa. 1991. Molecular and cellular aspects of early B-cell development. Curr. Opin. Immunol. 3:186-192.

48. Rolink, A., and F. Melchers. 1991. Molecular and cellular origins of B lymphocyte diversity. Cell. 66:1081-1094.

49. Schwaber, J. 1992. Evidence for failure of V(D)J recombination in bone marrow Pre-B cells from X-linked agammaglobulinemia. J. Clin. Invest. 89:2053-2059.

50. Cuisinier, A. M., V. Guigou, L. Boubli, M. Fougereau, and C. Tonnelle. 1989. Preferential expression of VH5 and VH6 immunoglobulin genes in early human B-cell ontogeny. Scand. J. Immunol. 30:493-497.

51. Berman, J. E., K. G. Nickerson, R. R. Pollock, J. E. Barth, R. K. B Schuurman, D. M. Knowles, L. Chess, and F. W. Alt. 1991. $\mathrm{V}_{\mathrm{H}}$ gene usage in humans: Biased usage of the $\mathrm{V}_{\mathrm{H}} 6$ gene in immature B lymphoid cells. Eur. $J$. Immunol. 21:1311-1314.

52. Cuisinier, A. M., L. Gauthier, L. Boubli, M. Fougereau, and C. Tonnelle. 1992. Mechanisms that generate human Immunoglobulin diversity operate from the 8th week of gestation in fetal liver. Eur. J. Immunol. 23:110-118.

53. Schroeder, H. W., J. J. L. Hillson, and R. M. Perimutter. 1987. Early restriction of the human antibody repertoire. Science (Wash. DC). 238:791-793.

54. Schroeder, H. W., Jr., and J. Y. Wang. 1990. Preferential utilization of conserved immunoglobulin heavy chain variable gene segments during human fetal life. Proc. Natl. Acad. Sci. USA. 87:6146-6150.

55. Yancopoulos, G. D., S. V. Desiderio, M. Paskind, J. F. Kearney, D. 
Baltimore, and F. W. Alt. 1984. Preferential utilization of the most JH-proximal VH gene segments in pre-B-cell lines. Nature (Lond.). 311:727-733.

56. Yancopoulos, G. D., B. A. Malynn, and F. W. Alt. 1988. Developmentally regulated and strain-specific expression of murine VH gene families. $J$. Exp. Med. 168:417-435.

57. Jeong, H. D. and J. M. Teale. 1988. Comparison of the fetal and adult functional B cell repertoires by analysis of $\mathrm{VH}$ gene family expression. $J$. Exp. Med. 168:589-603.

58. Sanz, I. 1991. Multiple mechanisms participate in the generation of diversity of human H chain CDR3 regions. J. Immunol. 147:1720-1729.

59. Gu, H. K. 1991. B cell development regulated by gene rearrangement: arrest of maturation by membrane-bound Dmu protein and selection of Dmu element reading frames. Cell. 65:47-54.

60. Gu, H., I. Forster, and K. Rajewsky. 1990. Sequence homologies, N sequence insertion and $\mathrm{JH}$ gene utilization in VHDJH joining: implications for the joining mechanism and the ontogenetic timing of Ly1 B cell and B-CLL progenitor generation. EMBO (Eur. Mol. Biol. Organ.) J. 9:2133-2140.

61. Feeney, A. J. 1990. Lack of $\mathrm{N}$ regions in fetal and neonatal mouse immunoglobulin V-D-J junctional sequences. J. Exp. Med. 172:1377-1390.

62. Pearl, E. R., L. B. Vogler, A. J. Okos, W. M. Crist, A. R. Lawton, and
M. D. Cooper. 1978. B lymphocyte precursors in human bone marrow. An analysis of normal individuals and patients with antibody deficiency states. $\mathrm{J}$. Immunol. 120:1169-1175.

63. Fu, S. M., J. N. Hurley, J. M. McCune, H. G. Kunkel, R. A. Good. 1980. Pre-B cells and other possible precursor lymphoid cell lines derived from patients with X-linked agammaglobulinemia. J. Exp. Med. 152:1519-1526.

64. Schwaber, J. and R. H. Chen. 1988. Premature termination of variable gene rearrangement in B lymphocytes from X-linked agammaglobulinemia. $J$. Clin. Invest. 81:2004-2009.

65. Costa, T. E. F., H. Suh, and M. C. Nussenzweig. 1992. Chromosomal position of rearranging gene segments influences allelic exclusion in transgenic mice. Proc. Natl. Acad. Sci. USA. 89:2205-2208.

66. Osman, G. E., P. H. Brodeur, N. Rosenberg, and H. H. Wortis. 1992. The Ig VH repertoire of fetal liver-derived Pre-B cells is influenced by the expression of a gene linked to X-linked immune deficiency. J. Immunol. 148:1928-1933.

67. Conley, M. E. 1985. B cells in patients with X-linked agammaglobulinemia. J. Immunol. 134:3070-3074.

68. Tedder, T. F., M. J. Crain, H. Kubagawa, L. T. Clement, and M. D. Cooper. 1985. Evaluation of lymphocyte differentiation in primary and secondary immunodeficiency diseases. J. Immunol. 135:1786-1791. 